\title{
Generic framework for meso-scale assessment of climate change hazards in coastal environments
}

\author{
Lars Rosendahl Appelquist
}

Received: 30 March 2012 / Accepted: 17 September 2012 /Published online: 17 October 2012

(C) The Author(s) 2012. This article is published with open access at Springerlink.com

\begin{abstract}
This paper presents a generic framework for assessing inherent climate change hazards in coastal environments through a combined coastal classification and hazard evaluation system. The framework is developed to be used at scales relevant for regional and national planning and aims to cover all coastal environments worldwide through a specially designed coastal classification system containing 113 generic coastal types. The framework provides information on the degree to which key climate change hazards are inherent in a particular coastal environment, and covers the hazards of ecosystem disruption, gradual inundation, salt water intrusion, erosion and flooding. The system includes a total of 565 individual hazard evaluations, each graduated into four different hazard levels based on a scientific literature review. The framework uses a simple assessment methodology with limited data and computing requirements, allowing for application in developing country settings. It is presented as a graphical tool - the Coastal Hazard Wheel - to ease its application for planning purposes.
\end{abstract}

Keywords Coastal management · Coastal classification · Climate change $\cdot$ Hazard assessment

\section{Introduction}

The growing concern for global climate change has spurred research into methods for assessing climate-related vulnerability of coastal environments at local, regional and national scale. Methods developed so far include various types of

L. Rosendahl Appelquist ( $\square)$

UNEP Risoe Centre, Department of Management Engineering,

Technical University of Denmark,

Frederiksborgvej 399,

4000 Roskilde, Denmark

e-mail: 1rap@dtu.dk coastal vulnerability index and indicators, GIS systems and modelling approaches (Ramieri et al. 2011). The existing methodologies, however, have mainly been designed for developed country assessments and all of them require a significant amount of input data and computing capacity, limiting their application in developing countries. Furthermore, most approaches group the different hazards together into a combined risk or vulnerability index, thereby losing some specificity relevant for planning purposes. The available sector specific approaches tend to focus on one particular risk type (Ramieri et al. 2011).

This paper presents a generic framework for simple assessment of climate change hazards in coastal environments without the need for excessive data collection or computer processing capacity. It is especially targeted decisionmakers in developing countries, where rapid changes in demography and land-use increase the need for regional and national planning along with tools supporting this effort. The framework aims at covering virtually all coastal environments worldwide through a specially designed coastal classification system building on key bio-geophysical parameters. It provides information on the climate change hazards considered most relevant for coastal management (Zhu et al. 2010). The framework is presented as a graphical tool - the Coastal Hazard Wheel (CHW) - to ease its application for regional and national planning, especially in developing countries.

The coastal classification system uses a geological categorization as basis, on which it adds the main dynamic forces and processes acting in the coastal environment and on the geological framework itself. Using this methodology, a total of 113 generic coastal environments have been defined and attempts have been made to keep the number of generic environments as low as possible while still maintaining the usefulness of the classification system seen from a decision-support perspective. The system allows the 
practical classification to be carried out through collection of on-site and remote sensing data or through primarily remote means. Whereas the first method produces the most reliable results, the latter may be appropriate for regional hazard assessments requiring less accuracy.

The inherent climate change hazards are defined as the hazards being an integral part of the bio-physical properties of a coastal environment when exposed to key climate change drivers. The climate change drivers considered in this regard are the ones defined in the IPCC Fourth Assessment Report and includes an increase in global average temperature of $1,1-6,4{ }^{\circ} \mathrm{C}$ by 2100 , a global sea level rise of $0,18-0,59 \mathrm{~m}$ by 2100 , an average rise in global sea surface temperature, an average decrease of ocean water $\mathrm{pH}$, a possible intensification of tropical cyclones and an possible alteration of precipitation/run-off patterns (IPCC 2007a).

The framework covers the inherent hazards related to ecosystem disruption, gradual inundation, salt water intrusion, erosion and flooding, and the graduation of the inherent hazards is carried out based on a scientific literature review. The hazard graduation is illustrated by a four-level number/colour code system. The inherent hazards may be mitigated by human alteration of the natural environment or other human actions, but since the framework is based on bio-geophysical parameters, the presence of a given hazard will remain the same unless the bio-physical properties of a coastal environment are changed permanently by human actions. Changes in natural drivers may also change the classification parameters over time, which will then impact the inherent hazard levels.

\section{The coastal classification system}

The coastal classification system constitutes the foundation for the inherent hazard assessment. It is developed particularly for decision-support but includes many components of previously published coastal classification systems. The system tries to incorporate the main static and dynamic parameters acknowledged in the paradigm of coastal morphodynamics (Wright and Thom 1977; Cowel and Thom 1994).

The bio-geophysical components used in the classification system are selected as the ones considered most important for the characteristics of a particular generic coastal environment. The components included are geological layout, wave exposure, tidal range, flora/fauna, sediment balance and storm climate. Each generic coastal system has a specific combination of these variables. Since the variables can change significantly over short spatial distances, a generic coastal environment will according to the classification system theoretically apply to a particular spot along a coastline. For practical application, however, a generic coastal environment should be considered to extend longshore until any of the included variables change significantly. In cases where a particular classification parameter is of minor importance, the system applies an Any phrase to avoid a disproportionate large number of categories. Variables such as local isostatic uplift/subsidence and sediment grain size have not been included as these to some extent are indirectly covered through other parameters. This is to achieve an appropriate balance between classification simplicity and correctly reflecting natural conditions. The different classification components have been clearly defined in order to differentiate the generic coastal environments and to make the classification system practical applicable. The definitions and classification assumptions are outlined in the following sections.

\section{Geological layout}

The geological layout constitutes the basis on which the dynamic processes act. It has been created by various past dynamic processes including glacial, fluvial, marine, volcanic and tectonic (Davis Jr and Fitzgerald 2004). The coastal landscape continues to be modified by these processes over different timescales and making an assessment of a particular geological layout will therefore be a snapshot that will change gradually over time. However, as most major changes in geological layout take place on timescales of decades or more, the effect of these changes on the classification is limited. Furthermore, the subsequent layers in the classification system include the major short-term coastal processes, meaning that most gradual natural changes are handled by the classification system.

The geological layouts included in the classification system are defined based on a thorough analysis of the world's costal environments and are framed in a way so they cover all major types of geological layouts worldwide. They are defined to include important generic characteristics while still maintaining an appropriate simplicity. The geological layout categories included are coastal plain; barrier; delta/ low estuary island; sloping soft rock coast; sloping hard rock coast; coral island; tidal inlet/sand spit/river mouth. The first four categories are sedimentary geological layouts generally found on trailing edge coastlines such as the Atlantic coast of North- and South America whereas the fifth category, sloping hard rock coast, is commonly found on leading edge coastlines such as the Pacific coast of North and South America. The coral island category is largely depending on tectonic and climatic conditions (Davis $\mathrm{Jr}$ and Fitzgerald 2004; Masselink and Hughes 2003). The final category tidal inlet/sand spit/river mouth constitutes a group of specially dynamic geologic environments.

The coastal plain category is defined as coasts with average slopes of less than 3-4\% at least $200 \mathrm{~m}$ inland of 
the MSL, and which are composed of sedimentary deposits such as clay, silt, sand, gravel, till or larger cobbles. If coastal dunes are present, the slope may locally be higher than 3-4\% where the backbeach meets the dunes, but the coast will still fall into the coastal plain category. Coastal plains are often formed by glacial and fluvial processes or through coastal progradation (Davis Jr and Fitzgerald 2004; Masselink and Hughes 2003).

The barrier category is defined as coasts that consist of shore parallel sedimentary bodies with cross distances ranging from less than $100 \mathrm{~m}$ to several kilometres, and lengths ranging from less than $100 \mathrm{~m}$ to over $100 \mathrm{~km}$ (Davis Jr and Fitzgerald 2004). Narrow barriers often exist where the sediment supply is or has been limited, while broad barriers are formed in areas with sediment abundance (Masselink and Hughes 2003). The seaward side of a barrier often contains a wave dominated beach environment, while the landward side consists of protected lagoons and estuaries with various kind of marsh or mangrove vegetation, depending on climatic conditions and tidal range. In meso- and macro-tidal environments, barriers are frequently cut by tidal inlets. In the classification system, a barrier can occur in parallel to coastlines of other Geological layouts, located landwards of the barrier. This would e.g. be the case where a coastal plain or sloping soft rock coast is located landwards of a barrier. If a barrier has a slope of more than 3-4\% it will fall into the sloping soft rock coast category.

The delta/low estuary island category is defined as coasts composed of fluvial transported sediment that is deposited in front of a river mouth. These landforms form in the coastal-fluvial interface where riverine sediment supplied to the coastline is not removed by marine processes. The formation of deltas/low estuary islands is therefore strongly dependent on the fluvial sediment discharge as well as the waves, tides and currents of a particular location. Plate tectonics and regional geological conditions also influence delta formation. Larger deltas are generally found on trailing edge and marginal sea coastlines, where large drainage basins provide a high fluvial discharge, and wide continental shelves provide a relatively shallow depositional area (Schwartz 2005). Examples of major deltas developed under these conditions are the Mississippi and Amazon deltas in the Atlantic Ocean and the Yangtze delta in the South China Sea (Davis Jr and Fitzgerald 2004). Small deltas might form along leading edge coastlines but their extension is limited by the smaller drainage basins and steep coastal gradient that does not allow significant sediment accumulation.

The sloping soft rock coast category is defined as coasts comprised of soft rock material with average slopes greater than $3-4 \%$ at least $200 \mathrm{~m}$ inland of the MSL. Coastal cliffs with a steep cliff gradient combined with shore platforms or a landscape flattening landwards of the steep cliff also fall into this category. Sloping soft rock coasts can be comprised of a range of different sedimentary material such as chalk, moderately cemented laterite, clay, silt, sand and till with larger pebbles or cobbles. Their geological origin can range from old uplifted seabed to more recent glacial deposits (Schwartz 2005). Hard sedimentary rocks are not included in this category and it can therefore be necessary to assess the level of sediment cementation in order to determine whether a particular coast should be classified as soft or hard rock. In the classification system, a rock will fall into the soft rock category if the sediment is poorly cemented and as a general rule, it should be possible to push a knife some centimetres into the rock material without using excessive force. Since sloping soft rock coasts can exist as both coastal cliffs and gently sloping vegetated hills, it may be necessary to remove some topsoil and vegetation to determine the cementation level in the field. If the classification is done remotely, geologic and geomorphologic maps, as well as the ground elevation function in Google Earth can be used.

The sloping hard rock coast category is defined as coasts consisting of igneous, sedimentary or metamorphic rock with any seaward slope greater than zero. Igneous rocks are formed from magma and are comprised of a range of different minerals and grain sizes depending on their chemical composition and solidification process. Sedimentary rocks consist of sediment that has undergone different stages of diagenesis, where the sediment has been compacted and cemented under increased temperature and pressure, creating a solid rock structure. Metamorphic rocks have formed from both igneous and sedimentary rocks when they have undergone recrystallization under high temperature and pressure (Press and Siever 2001). The specific physical and chemical rock properties influence the weathering and erosion processes, but for the coastal classification system, hard rock coasts are considered as one uniform group. Sloping hard rock coasts can be present in different forms such as coastal mountain chains, headlands and archipelagos.

The coral island category is defined as low lying coral islands in the form of tropical atolls and coral cays. Tropical atolls are open ocean coral islands that rest on a subsiding volcanic foundation. The coral base can be as old as 30 million years and reef material can be found at depths of over $1,000 \mathrm{~m}$ beneath the atoll. Atolls have a round shape with diameters ranging from a few kilometres to more than hundred (Schwartz 2005). Coral cays are younger islands formed on top of coral reefs or adjacent to atolls due to the accumulation of reef-derived sediment in one location as result of wave action. These islands can rise up to $3 \mathrm{~m}$ above high water level and can be composed of coarse reef fragments or fine carbonate sand. The beaches of both atolls and coral cays can have cemented to form beachrock and coral sandstone which help stabilize the islands (Haslett 2009).

The tidal inlet/sand spit/river mouth category is established as a separate grouping in the classification system as 
these environments can be highly morphologically active and respond quickly to changes in other coastal processes (Mangor 2004). In the classification system, tidal inlets are defined as the coastline of a tidal inlet itself and $1 \mathrm{~km}$ parallel to the shore on each side of the inlet. Tidal inlets are found along barrier coastlines throughout the world and provide water exchange between an open coast and adjacent lagoons and estuaries. Their morphology depend on a range of different parameters such as tidal range, wave climate and sediment availability (Davis Jr and Fitzgerald 2004). Sand spits are elongate sedimentary deposits that are formed from longshore currents losing their transport capacity and subsequently depositing sediment at particular locations. They can be present in different shapes and are generally classified into simple linear spits, recurved spits with hook-like appearances, and complex spits with plural hooks (Schwartz 2005). River mouths are defined as the coastline $1 \mathrm{~km}$ on each side of a well defined river mouth. Tidal inlets, sand spits and river mouths are assigned high priority in the classification system, meaning that e.g. a coastal plain will fall into this category if it is located less than $1 \mathrm{~km}$ on each side of a tidal inlet or river mouth.

\section{Wave exposure}

The wave exposure is the dominant energy source in the nearshore environment and a highly important parameter for the coastal morphodynamics. Even though some incoming wave energy is reflected by the shoreline, most energy is transformed to generate nearshore currents and sediment transport and is a key driver of morphological change (Masselink and Hughes 2003).

For most coastal systems, gravity waves generated by wind stress on the ocean surface are the main source of energy. The restoring force for this wave type is earth's gravity and gravity waves are generally composed of seaand swell waves (Masselink and Hughes 2003). Sea waves are formed under direct influence of the wind on the ocean surface and have peaked crests and broad troughs. They are often complicated with multiple superimposed sets of different wave sizes and whitecaps can be present during high wind speeds. Swell waves develop after the wind stops and where the waves travel outside the area where the wind is blowing. They have a sinusoidal shape and commonly have long wavelengths and small wave heights (Masselink and Hughes 2003). The wave height is the generally applied measure for incoming wave energy and is defined as the difference in elevation between the wave crest and wave trough (Davis Jr and Fitzgerald 2004). Since the wave energy increases as the square of the wave height, coastal environments with high wave heights have relatively high energy intensity compared to protected coasts (Thieler et al. 2000).
The classification system distinguishes between exposed, moderately exposed and protected coastlines. The distinction between these categories is based on the significant wave height, $\mathrm{H}_{\mathrm{S}}$, that represents the average wave height of the one-third highest waves in a wave record and corresponds well to the visual wave heights estimates (Masselink and Hughes 2003). To ensure consistency, the classification system uses the $\mathrm{H}_{\mathrm{S}} 12 \mathrm{~h} / \mathrm{yr}$, which is the nearshore significant wave height exceeded for $12 \mathrm{~h}$ per year (Mangor 2004). In this way, a uniform time record will be used when the assessment framework is applied in practice.

The wave exposure level is determined based on the coastline geography and wind climate. All coastlines located in regions with swell waves are in the classification system defined as moderately exposed (Mangor 2004). These coastlines can be indentified based on Fig. 1, where coasts falling into "West coast swell", "East coast swell" and "Trade/monsoon influences" are categorized as moderately exposed coastlines.

If the coastline is located outside the swell regions, the wave exposure should ideally be determined based on the SB-M method. This method uses a nomogram to predict $\mathrm{H}_{\mathrm{S}}$ by input of wind speed, wind duration and the fetch length (Masselink and Hughes 2003). For use in the nomogram, the wind speed $(U)$ in $\mathrm{m} / \mathrm{s}$ has to be converted to the wind stress factor, $U_{A}$, calculated from the equation below. For the calculation of $\mathrm{H}_{\mathrm{S}} 12 \mathrm{~h} / \mathrm{yr}$, the maximum average wind speed blowing on-shore for $12 \mathrm{~h} / \mathrm{yr}$ has to be used in the equation as $\mathrm{U}$.

$U A=0,71 * U^{1,23}$

(Masselink and Hughes 2003)

When reading the nomogram, the $\mathrm{H}_{\mathrm{S}} 12 \mathrm{~h} / \mathrm{y}$ can be found by plotting $\mathrm{U}_{\mathrm{A}}$ together with the $12 \mathrm{~h}$ of wind speed and the local fetch. Where the limiting parameter for $\mathrm{H}_{\mathrm{S}} 12 \mathrm{~h} / \mathrm{yr}$ is the fetch length, the fetch length becomes the determinant. The nomogram is shown in Fig. 2.

If the $\mathrm{H}_{\mathrm{S}} 12 \mathrm{~h} / \mathrm{y}$ is determined as more than $3 \mathrm{~m}$, the coast is considered exposed, while it is considered moderately exposed with an $\mathrm{H}_{\mathrm{S}} 12 \mathrm{~h} / \mathrm{y}$ of $1-3 \mathrm{~m}$. If the $\mathrm{H}_{\mathrm{S}} 12 \mathrm{~h} / \mathrm{y}$ is determined as less than $1 \mathrm{~m}$, the coast is considered to be protected.

Since it can be difficult to obtain the necessary wind data to apply the S-B-M method, especially in developing countries, the free fetch can be used to roughly estimate the exposure levels of non-swell coastlines. Coasts can be considered exposed if they border waterbodies larger than $100 \mathrm{~km}$, while they can be considered moderately exposed if they are associated with waterbodies of the size of approximately $10-100 \mathrm{~km}$. Protected coasts are generally restricted to inner waterbodies in the order of less than $10 \mathrm{~km}$, but can also be seen along larger waterbodies with shallow nearshore zones or mild on-shore wind climates (Mangor 2004). When estimating the exposure levels, either through the S-B-M method or roughly through 
Fig. 1 Global wave climates (Davies 1980, modified by Masselink and Hughes 2003)

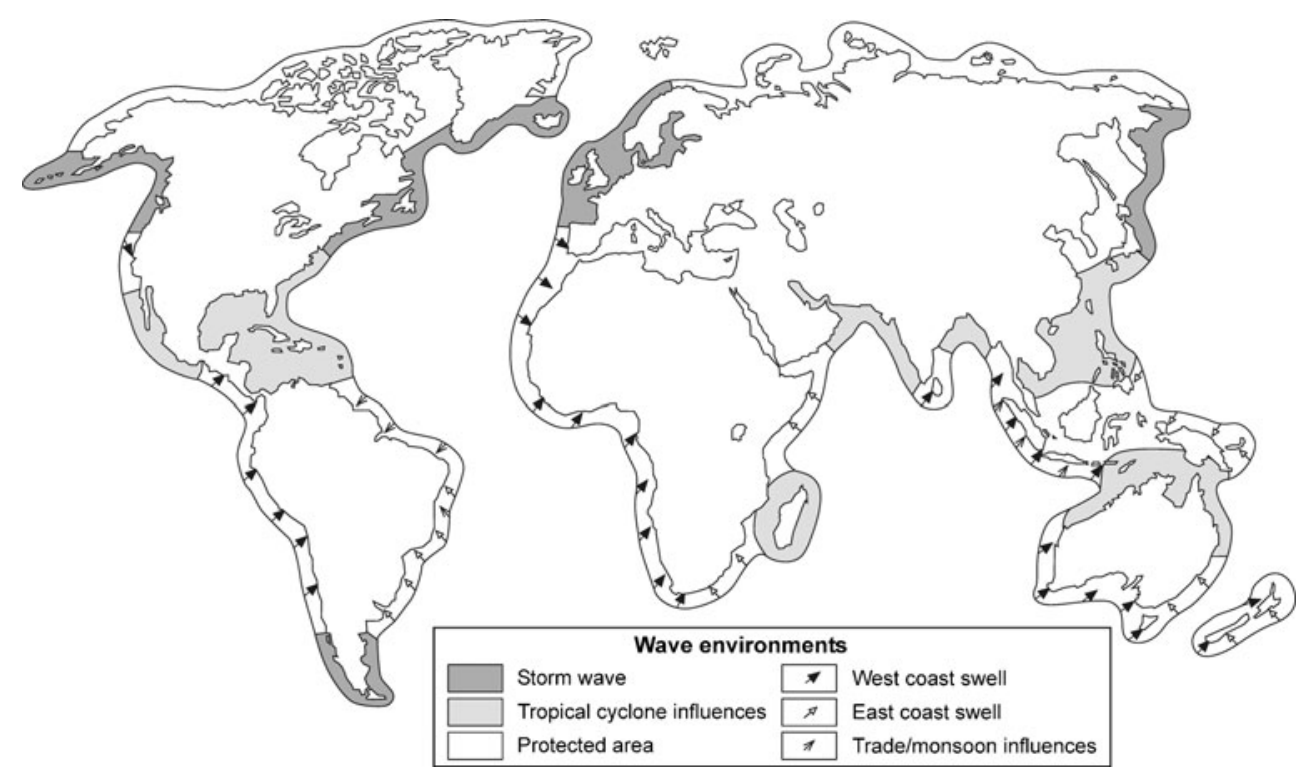

the free fetch, it is therefore important to be aware of physical conditions such as coastal reefs or tidal flats that cause the coast to fall into the protected category even when the water body is larger than $10 \mathrm{~km}$. Ice affected coastlines may have seasonal fluctuating wave exposures due to presence of winter sea ice. As sea ice is expected to be highly vulnerable to climate change, however, the same approach as for ice free coasts should be applied. Only in locations where the sea ice is

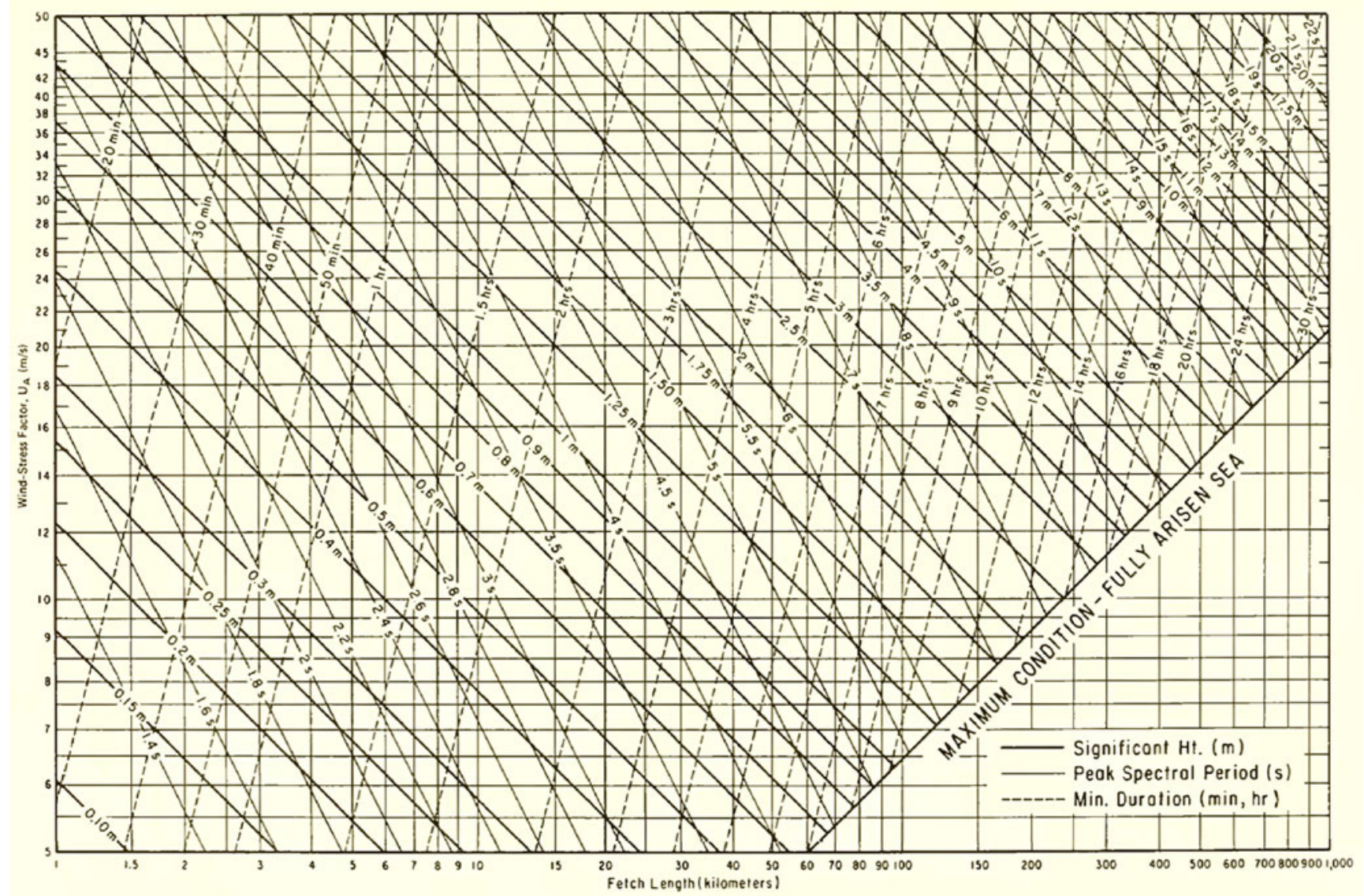

Fig. 2 Nomogram of deepwater significant wave prediction curves as function of wind speed, fetch length and wind duration (Coastal Engineering Research Center 1984) 
expected to be very stable, the fetch length has to take into account the ice cover.

\section{Tidal range}

Tides can have major impact on shoreline processes and on the development of coastal landforms. They are a manifestation of the moon's and sun's gravitational force acting on earth's hydrosphere and are present in the form of oceanic waves with wavelengths of thousands kilometres, resulting in periodic fluctuations in coastal water levels (Davis Jr and Fitzgerald 2004). Tides fluctuate on a daily basis following diurnal, semidiurnal and mixed tidal cycles (Davis Jr and Fitzgerald 2004). Diurnal tides exhibit one tidal cycle daily whereas semidiurnal tides exhibits two cycles daily. Mixed tides have components of both diurnal and semidiurnal tides varying throughout the lunar cycle (Davis Jr and Fitzgerald 2004). Globally, semidiurnal and mixed tides are dominating coastal areas (Haslett 2009).

From a morphodynamic perspective, the tidal range influences coastal processes in many ways and are controlling the horizontal extent of the intertidal zone, the vertical distance over which coastal processes operate and the area being exposed and submerged during a tidal cycle (Haslett 2009). The tidal range is defined as the height difference between the high water and low water during a tidal cycle (Schwartz 2005), and the tidal range of a particular coastal location is controlled by a range of different parameters including the distance from an oceanic amphidromic point, the local bathymetry, the width of the continental shelf and the coastal configuration (Haslett 2009). Generally, the tidal range increases with distance from an amphidromic point, with a bathymetric focus of the tidal wave on a particular coastal stretch, with a shallow continental shelf and with a coastline restriction, as in the case of gulfs and estuaries. Equally, a lower tidal range is present where the coast is close to an amphidromic point, does not has significant magnifying bathymetric conditions, has a narrow continental shelf and has an open coastline (Haslett 2009). The numerical value of the tidal range vary significantly between coastal locations and span from almost zero to about $16 \mathrm{~m}$ in funnel shaped embayments such as the Bay of Fundy, Canada (Davis Jr and Fitzgerald 2004). Tides of a particular location also fluctuate daily depending on planetary positions.

For classification purposes, coastlines can be grouped into various tidal environments based on tidal range, and a generally used classification system operates with the three main categories micro-tidal, meso-tidal and macro-tidal (Schwartz 2005). Micro-tidal environments are defined as coasts where the tidal range does not exceed $2 \mathrm{~m}$ and can be found on open ocean coastlines such as the eastern seaboard of Australia and the majority of the African Atlantic coast (Haslett 2009). Meso-tidal environments are defined as coasts with a tidal range of 2-4 $\mathrm{m}$ and examples of these are found on the Malaysian and Indonesian coasts and on the eastern seaboard of Africa (Haslett 2009). Macro-tidal environments are defined as coasts where the tidal range exceeds $4 \mathrm{~m}$ which is the case along some of the northwestEuropean coasts and in parts of north-eastern North America (Haslett 2009). The global distribution of micro-, meso- and macro-tidal environments is shown in Fig. 3.

The effect of tidal range on coastal morphodynamics is largely influenced by the local wave conditions. Therefore, the relative size of tides and waves of a particular location is - seen from a morphodynamic perspective - more important than the magnitude of the tidal range itself (Masselink and Hughes 2003). This relationship is illustrated by the relative tidal range expression that states that the relative morphodynamic importance of the tidal range decreases with increasing wave exposure (Masselink and Hughes 2003). This principle is applied in the classification system that uses the three different tidal categories, micro, meso/macro and any that are applied in accordance with wave exposure. Where the coastline is exposed or moderately exposed, the classification uses the any tide category as these environments are considered to be largely dominated by wave processes. This may lead to some inaccuracies in the hazard assessment of coastlines with a very large tidal range but is considered a reasonable simplification taking the impacts of other classification parameters into account. At protected coastlines, the tidal range can have major impact on the coastal morphodynamics and the classification system therefore distinguishes between micro and meso/macro-tidal conditions. Under micro-tidal conditions, these coastlines will still be partly wave dominated whereas they will be largely tide dominated under meso/macro-tidal conditions. The merging of meso/ macro tides is regarded as an acceptable simplification without major implications for a reliable hazard evaluation, except under extreme high tidal range conditions. Since the effect of tidal range on the inherent hazards of sloping soft rock coasts, sloping hard rock coasts and coral islands is considered to be minor, the any tide category has been applied to these layouts for simplification purposes. In the case of tidal inlets, tidal forces play a key role for their morphodynamics, but these environments are included in a separate category due to their special properties.

\section{Flora/fauna}

For some coastal environments, the local flora/fauna constitutes an important parameter for their morphodynamics and inherent climate change hazards. In the classification system, the flora/fauna has been included where it is considered to play an important role for the characteristics and inherent hazard profile of a coastal environment. The integration of the flora/fauna component in the classification system is complicated by its interdependence with other physical classification parameters and this is reflected in 
Fig. 3 Map over global variation in tidal range (Davies 1980, modified by Masselink and Hughes 2003)

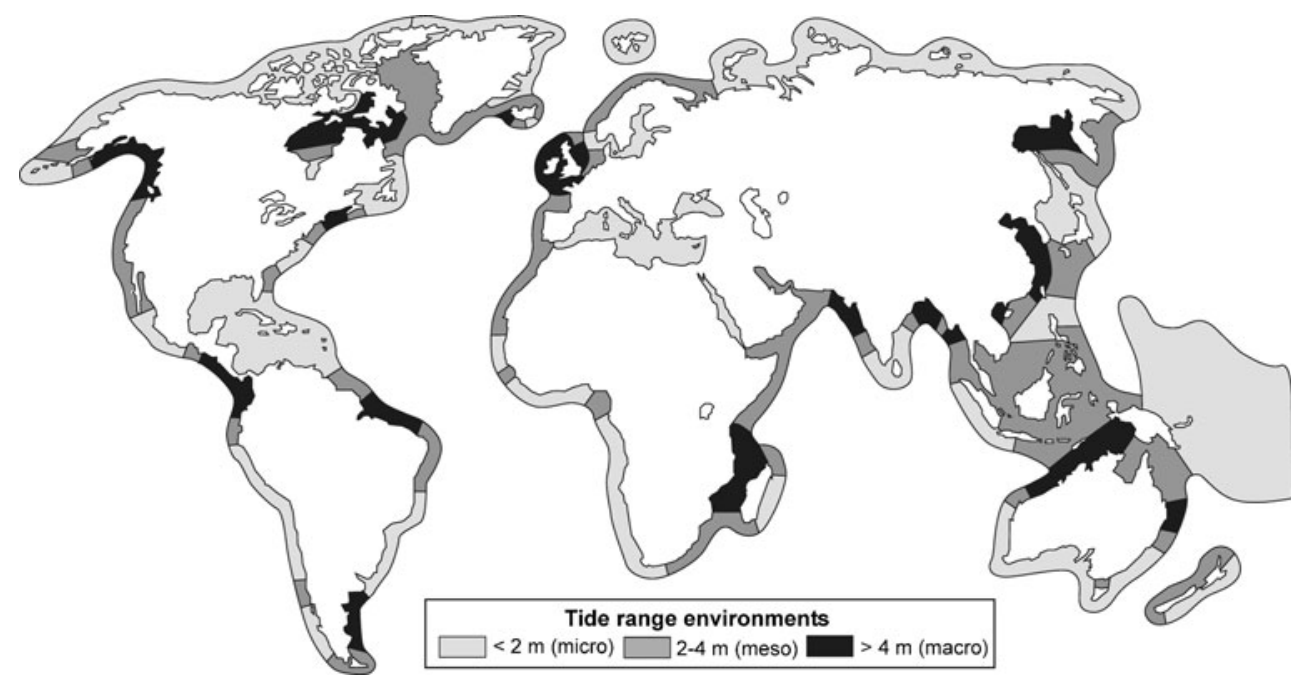

the application of the flora/fauna categories. In total, the classification system operates with eight different categories namely intermittent marsh; intermittent mangrove; marsh/ tidal flat; mangrove; vegetated; not vegetated; coral and any.

The intermittent marsh and marsh/tidal flat categories are applied to coastlines whose geological layout falls into the categories coastal plain, barrier and delta/low estuary island. The marsh is a grass-like vegetation of salty and brackish areas along protected, low energy coastlines. It colonizes higher parts of the intertidal environment, forming coastal wetlands that act as a sediment trap for fine grained sediment. Marsh areas gradually build up from continuous flooding and subsequent sediment deposition, which can be particularly large during storm events. Due to the continuous accumulation of sediment, marsh areas can to some degree follow sea level rise but will eventually drown if sea level rises too rapidly. In locations with a high tidal range, marsh areas are often continuous and combined with extensive tidal flats and the classification therefore distinguishes between the intermittent marsh category applied to areas with micro-tidal conditions and the marsh/tidal flat category applied to areas with meso/macro-tides.

The intermittent mangrove and mangrove categories are applied to coastlines falling into the geological layout categories coastal plain, barrier and delta/low estuary island. Mangrove is a woody shrub vegetation that grows along protected, low energy coastlines forming a swampy environment. It is very dependent on air temperature and cannot tolerate a freeze and its geographical extension is therefore limited to low and moderate latitudes. The extensive root network of mangroves acts as an efficient trap for fine grained sediment and reduces wave erosion of the coastline. Like marsh areas, mangrove forests are rich ecosystems providing nursing grounds for many animals and in addition limit erosion and flooding from tropical storms. In the classification system, the intermittent mangrove category is applied to areas with micro-tidal conditions, while the mangrove category is applied to areas with meso/macro-tides, as they colonise the tidal flats.

The vegetated and not vegetated categories are applied to the geological layout category sloping soft rock coast where vegetation of the coastal slopes plays an important role for the coastline characteristics. The vegetated category is applied when more than $25 \%$ of the slope is covered with vegetation while the not vegetated category is used when less than $25 \%$ is vegetated. Possible vegetation includes different grasses, scrubs and trees depending on the soft rock properties, slope and climatic conditions. Although some types of vegetation have a better stabilizing effect than others, the important criteria seen from a coastal classification perspective is whether the coastal slope is vegetated or not. Sloping soft rock coasts may be fronted by a narrow band of marsh or mangrove vegetation but this is not considered of major importance from an inherent hazard perspective. In cases where the fronting marsh or mangrove areas are extensive, the coastline will automatically fall into one of the non-sloping geological layout categories.

The coral category is applied to sloping rocky coasts where the corals have a firm substrate to thrive on. Corals are carnivorous suspension feeders living as polyps with an external skeleton of calcium carbonate (Masselink and Hughes 2003). They live in large colonies and reproduce by asexual polyp division or sexually during short periods of the year. As new coral larvae have limited swimming capabilities their end destination is very dependent on ocean currents and the duration of the planctonic phase and when they find a suitable substrate, they attach to it and transform into a polyp. Since they generally attach to hard substrates, rocky shorelines provide suitable coral habitats (Masselink 
and Hughes 2003). Reef building coral species only thrive in water temperatures between $18{ }^{\circ} \mathrm{C}$ and $34{ }^{\circ} \mathrm{C}$ and are thus limited to tropical and subtropical environments (Davis $\mathrm{Jr}$ and Fitzgerald 2004). Reef building corals are very light sensitive and reefs are rarely being created at depths greater than $50 \mathrm{~m}$. Locally, water turbidity and salinity can be important parameters for reef formation and high turbidity can decrease light penetration and increase sedimentation, thereby inhibiting coral growth. Salinity levels outside the range of 27-40 ppt also limit reef formation and low salinity combined with high turbidity often explain the reef openings found close to river mouths (Masselink and Hughes 2003). Corals can survive in high energy wave environments and even shows enhanced growth on exposed coastlines (Masselink and Hughes 2003). In the classification system, the coral category includes both fringing and barrier reefs fronting rocky coastlines. As coral reefs often are backed by carbonate beaches and not bare rock, a special beach category is available in the classification system for sloping hard rock coasts. The separate geological layout category for coral islands is assumed to be associated with coral reef environments of various kinds.

The any category (also indicated with an A in the CHW) is used when the flora/fauna is not considered to play an important role for the coastal characteristics and/or inherent hazard profile. In some cases, the flora/fauna may have relevant functions such as the ability of lyme grasses to reduce aeolian sediment transport, but compared to the other classification parameters it is not expected to influence the included hazards significantly.

\section{Sediment balance}

The sediment balance is an essential morphodynamic parameter and particularly important for coastlines falling into the sedimentary layout categories. The sediment balance determines whether there is a net accumulation, removal or balance of sediment at a particular coastline over time and is largely determined by the sediment transport and availability.

The coastal sediment transport can be divided into two main categories, namely transport of non-cohesive and cohesive sediment. Transport of non-cohesive, sand-sized sediment, termed littoral transport, plays an essential role for the sediment balance of exposed and moderately exposed sedimentary coastlines. This type of transport is mainly controlled by the wave height, wave incidence angle and sediment grain size, and large quantities of sediment can be transported down the coastline by this process (Mangor 2004; Davis Davis Jr and Fitzgerald 2004). Coastlines dominated by littoral sediment transport generally respond to physical changes by adjusting their theoretical equilibrium profile, which is the average characteristic form of a coastal profile, controlled by sediment grain size and to some degree wave conditions. Changes in sediment availability, storm conditions or sea level will cause the theoretical equilibrium profile to shift to a new equilibrium state that matches the changing framework conditions. Because of this mechanism, a coastal profile will require more sand to maintain its existing shoreline position if a new equilibrium profile is created due to sea level rise. This will lead to shoreline erosion if no net sediment supply is present.

Transport of fine, cohesive sediment or mud plays an important role in the sediment balance of protected coastal areas. Cohesive sediment particles have a relatively low fall velocity compared to sand grains and the individual grains have the ability to cohere to each other. These particles cannot form stable coastal profiles in exposed and moderately exposed coastlines since they easily go into suspension. Fine grained, muddy coasts are therefore only found in protected coastal areas where there is abundance of cohesive sediment. Such coastlines are generally vegetated with marsh or mangrove vegetation, sometimes combined with mud/tidal flats (Mangor 2004). Coastlines dominated by cohesive sediment can respond to rising sea level by growing vertically by increasing the sediment accumulation rate, but may also suffer from inundation and erosion depending on sediment availability and tidal dynamics.

In the classification system, the sediment balance section includes the two main categories balance/deficit and surplus and the two special categories no beach and beach that applies to rocky coastlines. It has been decided to group the balance/ deficit categories together to simplify the classification system and to ease the difficult evaluation of the sediment balance onsite or remotely. Coastal areas that are currently experiencing sediment deficits or only have sufficient sediment to remain stable at current conditions are likely to suffer from sediment deficits with a rising sea level, unless new sediment sources emerge (Haslett 2009). Coastal areas that currently experience sediment surplus might suffer deficits at a later stage if sea level rises sufficiently or there is a change in local sediment dynamics. However, seen from a inherent hazard perspective, these coastlines are less likely to experience severe sediment deficits in the near future.

For achieving an optimal accuracy of the hazard assessment, temporal data on sediment transport, erosion and accumulation would be valuable for determining the sediment balance of a particular coastline. As the assessment framework is intended to be used in areas with limited data availability, however, it is designed to rely on a combination of remote sensing data and on-site assessments. Direct short-term observations are complicated by the fact that single storm and high-wave events can lead to temporal coastline erosion which is reversed during calm conditions, thus causing fluctuating erosion and accumulation patterns (Mangor 2004; Stive et al. 2002). This means that a particular coastal area may one day appear to erode while looking 
stable sometime later. For evaluation of the sediment balance, it is therefore recommended to make use remote sensing techniques, such as the Google Earth timeline function, to evaluate coastal changes over several years. If possible, this should be combined with local field assessments of signs of coastal stability, erosion or accretion, along with interviews of local coastal inhabitants.

In cases where there is doubt about the validity of the sediment balance evaluation, it is recommended to be guided by the precautionary principle and apply the balancel deficit category, as this gives the highest general hazard level. This is also recommended where there is suspicion of human alteration of the sediment balance, such as by local or nearby beach nourishment. For rocky coastlines, the classification system does not require a sediment balance evaluation but simply apply a no beach category if the coast consists of bare rock and a beach category if some kind of beach environment is present.

\section{Storm climate}

In areas with tropical cyclones, coastal areas can experience extreme wind, wave, and precipitation conditions that significantly affect the coastal morphodynamics and inherent hazard profile. Tropical cyclones are generated over tropical seas where the water temperature exceeds $27^{\circ} \mathrm{C}$. They are normally generated between $5^{\circ}-15^{\circ} \mathrm{N}$ and $5^{\circ}-15^{\circ} \mathrm{S}$ and about 60 tropical cyclones are generated annually worldwide with peak periods in September in the Northern Hemisphere and in January in the Southern Hemisphere (Mangor 2004). Wind speeds in tropical cyclones exceed $32 \mathrm{~m} / \mathrm{s}$ and can cause extreme wave heights, storm surges and cloudburst. Although tropical cyclones have a great impact on the coastal morphology when they hit, the general coastal morphology of an area is largely determined by the local wave climate (Mangor 2004).

The classification system distinguishes between locations with and without tropical cyclone activity, without considering their frequency. This is decided as tropical cyclones contribute to the inherent hazards in all areas where they occur regardless of their frequency. The classification system uses the map shown earlier in Fig. 1 to categorize the influence of tropical cyclones on coastal areas (Masselink and Hughes 2003). In areas indicated to be under "Tropical cyclone influence" the classification system applies a yes to tropical cyclone activity while it applies a no for locations outside these areas.

\section{The inherent hazard assessment}

The inherent hazard graduation for the generic coastal environments is based on a review of the scientific literature on the susceptibility of coastal systems to climate changerelated hazards. As the literature mainly addresses the susceptibility of different coastal sub-systems, the hazard graduation is based on a qualitative analysis of how the various hazards apply to the coastal categories defined in the classification system. This approach is surrounded by some uncertainty and the hazard graduation therefore only distinguishes between four different hazard levels, depending on the hazard presence. It is believed that the four-grade system provides sufficient information to be relevant for regional planning purposes, while at the same time appropriately reflecting the uncertainties associated with the hazard graduation methodology.

The four levels included are defined so that 4 equals very high hazard presence, 3 equals high hazard presence, 2 equals moderate hazard presence and 1 equals low hazard presence. Each generic environment has been assigned a specific inherent hazard level for ecosystem disruption, gradual inundation, salt water intrusion, erosion and flooding, and in the CHW, the graduation is displayed as a combined number/colour code to give the user the best possible overview of the many subsections. A total of 565 individual hazard evaluations are assigned to the 113 different coastal systems. The following sections highlight some of the key parameters determining the inherent hazard levels based on the scientific literature review.

\section{Ecosystem disruption}

The graduation of inherent hazards for ecosystem disruption is based on the complexity, sensitivity and expected response to climate change of a particular ecosystem associated with a generic coastal environment. Where the flora/ fauna category is specified in the classification system, the ecosystem sensitivity applies to this particular biological framework, whereas the sensitivity applies to the broader biological framework for coastlines where the flora/fauna category has not been explicitly specified.

For exposed and moderately exposed littoral coastal environments, the inherent hazard levels are generally low, as these environments represent hostile places for biota. The littoral coastlines have a limited flora, and the fauna are mainly composed of micro- and meiofauna living beneath the sand surface. The projected increase in sea surface temperature is unlikely to cause significantly disruption of these ecosystems as the animals living here are used to adjust to large temperature fluctuations. The ecosystems may, however, to some degree be sensitive to beach erosion (Brown and McLachlan 2002).

Protected coastal environments often have greater ecological diversity than littoral/exposed coastlines, when coral coasts are disregarded (Schwartz 2005). This is especially the case for coastlines with a large tidal range, as these environments frequently host complex and extensive 
ecosystems such as marsh, mangrove and tidal flat environments (Haslett 2009). Marshes are generally characterized by high primary production and high species diversity and provides nursing grounds for a range of different marine animals including fish species (Simas et al. 2001). Together with adjacent tidal flat environments, these areas also constitute important habitats for bird populations (Hails 1997). Their response to climate change highly depends on their ability to keep up with sea level rise and hence the sediment availability (IPCC 2007b). Mangrove environments are highly complex ecosystems with a high primary productivity. They are among the most productive ecosystems on earth and material export from mangrove forests provide organic matter that acts as an food and energy source for marine primary and secondary production (McMullen and Jabbour 2009; Jennerjahn and Ittekkot 2002). Climate change combined with stressors from human activities such as clearing of mangroves for aquaculture poses a risk to the diversity of coastal mangroves (IPCC 2007b). Yet, mangroves have demonstrated a high resilience to change over historic time scales (Gilman et al. 2008). Climate change is projected to cause a maximum loss of global mangrove forests of $10-15 \%$ which is secondary to current rates of human deforestation (Alongi 2008). Mangroves occupying low relief islands or carbonate beaches with limited sediment supply are generally considered especially vulnerable (Alongi 2008). Protected coasts with a low tidal range generally have an increased risk of wetland loss (Nicholls 2004).

Coral reef environments are among the most biologically diverse ecosystems on the planet (Hoegh-Guldberg et al. 2007). They are expected to be highly sensitive to climate change and especially at risk from increasing ocean temperature and ocean acidification (McMullen and Jabbour 2009). Mass coral bleaching is clearly correlated with rises of sea surface temperature of short duration above summer maxima (Lesser 2004; McWillams et al. 2005) although it is still unclear whether bleaching takes place as an adaptive symbiotic strategy or as a symptom of damage caused by changing environmental conditions (Douglas 2003). It is considered very likely that a projected sea surface temperature increase of $1-3{ }^{\circ} \mathrm{C}$ will result in more frequent bleaching events and coral mortality if significant thermal adaptation is not taking place (IPCC 2007b; Sheppard 2003). With the currently predicted temperature increase, bleaching could eliminate shallow-water corals within a few decades (Hallock 2005). The increased acidification of sea water and the decreasing carbonate-ion concentration will reduce the calcification rates of marine organisms including reef-building corals (Hoegh-Guldberg et al. 2007; Guinotte et al. 2003). Experimental studies have shown that a doubling of pre-industrial atmospheric $\mathrm{CO}_{2}$ concentration decreases coral calcification rates and growth by up to $40 \%$
(Hoegh-Guldberg et al. 2007). The projected reduction in oceanic $\mathrm{pH}$ can be as much as $0,4 \mathrm{pH}$ units by the end of this century and ocean carbonate levels may drop below the level for sustaining coral reef accretion by 2050 (Hoegh-Guldberg et al. 2007). Coral reefs are expected to be able to keep up with sea level rise over the next decades, but this may be of minor importance as they are likely to suffer from the changes in water temperature and acidification (IPCC 2007b). Furthermore, intensification of tropical cyclones could have very damaging effects on coral reefs (IPCC 2007b).

Along with the sensitive coral reef ecosystems associated with coral islands, freshwater dependant ecosystems on these locations often harbour rare and endemic species. These ecosystems are highly sensitive to sea level rise and the associated risk salt water intrusion (McMullen and Jabbour 2009).

\section{Gradual inundation}

The graduation of inherent hazards for gradual inundation reflects the possibility of a gradual submergence of a coastal environment due to climate change. Contrary to flooding, gradual inundation takes place over years and decades, when the sediment deposition and growth of biological organisms cannot follow suit with the rising sea level.

Coastlines with a flat geological layout such as coastal plains, barriers, deltas and coral islands generally have a higher inherent hazard level. Coastal floodplains can be inundated due to natural levee overtopping if the sediment supply cannot keep up with the sea level rise, while inundation of delta environments depends on the balance between fluvial sediment supply and coastal emergence (IPCC 2007b). Delta environments are generally very sensitive to sea level rise (Ericson et al. 2006; Woodroffe et al. 2006) and rates of sea level rise in deltas tend to be greater than the global average due to delta subsistence (IPCC 2007b). Most deltas no longer maintain their natural sediment supply due to upstream damming activities and experience sediment deficits as they are subsiding due to the weight of the accumulated sediment (Masselink and Hughes 2003). Other human activities such as withdrawal of oil, gas and groundwater contribute further to delta subsidence (Ericson et al. 2006), and many delta environments are already changing rapidly, even before human induced sea level rise has stated to accelerate (IPCC 2007b).

Exposed and moderately exposed littoral coastlines are generally expected to respond to sea level rise through adjustments in their theoretical equilibrium profile with associated coastal erosion if no additional sediment is supplied to the coast (Masselink and Hughes 2003). Gradual inundation will therefore often be a secondary effect of sea level rise for these coastlines. Protected coastlines, on the other hand, will be particularly susceptible to gradual inundation and for these coastlines, the sediment balance is essential 
for their ability to follow sea level rise through vertical sediment accretion (Haslett 2009; Richards et al. 2008). If enough sediment is available, marsh, mangrove and tidal flat areas may be able to follow a rising sea level through vertical accretion while they are likely to drown in locations with a low sediment supply. Along with sediment availability, tidal range also influences inundation hazards and marsh areas with a high tidal range are generally considered to be less vulnerable to sea level rise (Simas et al. 2001).

While marsh and tidal flat areas may be able to follow a rising sea level in areas with sufficient sediment supply, they are still at risk if sea level rises too rapidly. Studies conclude that a widespread submergence of the Wadden Sea is projected if the sea level rise exceeds $10 \mathrm{~mm} / \mathrm{yr}$ (Van Goor et al. 2003). If a marsh area cannot keep pace with a rising sea level, it will begin to migrate inland if enough accommodation space is available. If human activities are limiting this migration, the total marsh area is likely to decrease due to coastal squeeze (Haslett 2009).

Mangrove coastlines are in many cases likely to migrate landwards with a rising sea level (Alongi 2008; Ross et al. 2000). Sea level rise is considered the greatest climatic threat to mangrove forests and currently most mangrove sediment surfaces are not keeping pace with sea level rise (Gilman et al. 2008). Some studies indicate, however, that mangroves may be able to tolerate significant sea level rise (Morris et al. 2002). The stability of mangrove forests is likely to depend on the sediment availability, together with the ability of mangroves to produce sufficient organic material to maintain their peat foundation during a rising sea level (Simas et al. 2001). In locations with a high tidal range, mangroves migrating landwards are likely to be supported by sediment eroded from the outer intertidal zone. In delta environments where delta plains of mangroves have been created following shoreline progradation, mangroves are at particular risk as they are unable to migrate landwards (Wodroffe 1995). As with marsh environments, coastal squeeze may limit the landward migration of mangrove forests, decreasing their total areal extension (Haslett 2009).

Coral reef environments may be at risk from gradual drowning if they fail to keep up with the rising sea level. Calculations of coral reef growth and geological core studies estimate the upward growth of coral reefs to 1-10 mm/year (Masselink and Hughes 2003), and it is expected that a sea levels rise greater than $20 \mathrm{~mm} /$ year would lead to coral drowning (Spencer 1994). Although gradual inundation of corals may become an issue with a rapid sea level rise, it is considered a minor risk compared to the expected increase in sea surface temperature and ocean acidification (Hoegh-Guldberg et al. 2007; IPCC 2007b).

\section{Salt water intrusion}

The graduation of inherent hazards for salt water intrusion reflects the possibility of salty sea water penetrating into coastal surface waters and groundwater aquifers. Many coastal groundwater aquifers are already experiencing salt water intrusion and it is expected that this phenomenon will be exacerbated by future sea level rise (Essink 2001). Shallow water aquifers are particularly at risk and in many places they already suffer from extensive salt water problems due to both natural and anthropogenic causes (Essink 2001). The intrusion of salt water can pose a great threat to future public water supply, agriculture and horticulture (Essink 2001) as well as pose a threat to existing natural ecosystems (Burkett and Kusler 2000).

The risk of salt water intrusion is controlled by a combination of coastal geology, aquifer dimensions, human groundwater withdrawal, surface water recharge, submarine groundwater discharge and local precipitation (IPCC 2007b). Coastal areas with a flat geological layout are generally more susceptible for salinisation of shallow aquifers as gradual inundation, erosion and higher flooding levels increases the landward reach of waves and storm surges (IPCC 2007b). Shoreline retreat can affect coastal aquifers by reducing the width and area of sand dunes, thereby diminishing the length over which groundwater recharge occurs (Essink 2001). Deltas and estuaries will experience increased salt water intrusion from sea level rise if these environments cannot keep pace with the rising sea level, and in locations with low sediment availability, nearby aquifers can be especially threatened (Essink 2001).

Salt water encroachment from sea level rise may eliminate some species living in brackish coastal wetland habitats, and climate change is likely to have most impact on brakish and freshwater marshes due to changes in hydrological regimes (Burkett and Kusler 2000; Sun et al. 2002). In areas with decreasing rainfall and increasing evaporation, mangroves can experience decreased productivity and decreased seedling survival due to conversion of upper tidal zones to hypersaline flats (Gilman et al. 2008). Many small islands are likely to experience increased water stress and depletion of freshwater lenses due to changing precipitation patterns and rising sea level (IPCC 2007b).

Yet, the risk of saltwater intrusion is largely related to human water extraction, and the presence of this hazard therefore arises from a combination of human and natural conditions (IPCC 2007b; Essink 2001). In the assessment framework, however, the focus is solely on the natural inherent hazards.

\section{Erosion}

The graduation of inherent hazards for erosion reflects the possibility of future coastline erosion and is controlled by a range of classification parameters. The geological layout expresses the potential erodability of the coastline and thus determining if any significant erosion can happen in the first 
place (Davis Jr and Fitzgerald 2004). Geological layouts of sedimentary origin have a relative high erodability, while hard rock coastlines show little erosion over timescales used in coastal management (IPCC 2007b). Where beach environments are present along hard rocky coastlines, erosion of the beach environment may occur while the rocky coastline itself is likely to remain stable (Masselink and Hughes 2003). The slope of the geological layout is also influencing the erosion rates as coastlines with a low slope generally retreat faster than steeper coastlines (Thieler et al. 2000). Yet, soft rock cliffs are still likely to retreat more rapidly in the future due to an increased erosion of the cliff profile from a rising sea level, a possible increase in precipitation intensity and higher groundwater levels. Soft rock cliff erosion often takes place in episodic intervals and the rate of erosion is controlled by a range of parameters including sea level rise, precipitation, wave exposure and sediment balance (IPCC 2007b). Barrier coastlines may, due to a rising sea level, migrate landwards through erosion, overwash and loss of sediment and in some cases barrier overstretching can lead to barrier breaching and disintegration (Haslett 2009). This can cause secondary effects by gradually or abruptly transforming protected backbarrier environments into high energy coasts (Stone and McBride 1998). Infilling of estuaries and lagoons with sediment during rising sea level can lead to major sediment deficits at coastlines in the vicinity of tidal inlets (Van Goor et al. 2003).

In exposed and moderately exposed littoral environments, the wave exposure is a key parameter for sediment transport, and in areas with negative sediment balance, high wave exposure can lead to significant coastal erosion due to loss of large quantities of sediment by offshore and longshore transport (Mangor 2004). In areas with current sediment surplus, high wave exposure will not necessarily lead to erosion, unless future sea level rise happens faster than sediment is supplied to compensate the changing theoretical equilibrium profile. Moreover, at any coastline with littoral sediment transport, there is a risk that local changes in wave and current conditions due to climate change could modify the rate and direction of the littoral transport (Masselink and Hughes 2003). Increased frequency and intensity of storms are likely to lead to escalated beach erosion (Brown and McLachlan 2002), and changes in sediment sources such as fluvial sediment supply can shift a sediment surplus into a deficit. Generally, the Bruun rule can be used to estimate the effects of sea level rise on littoral coastlines and a shoreline retreat is estimated to be 50-200 times the rise in relative sea level (IPCC 2007b).

In protected coastal environments, a high tidal range can be important for the sedimentation processes. In these environments, a sediment surplus can lead to a gradual sediment accumulation that keeps pace with the sea level rise. A sediment deficit, on the other hand, will lead to gradual inundation and various degrees of erosion (Masselink and Hughes 2003). The flora/fauna is important in protected coastal areas as marsh and mangrove vegetation can trap sediment and keep it deposited during extreme storm events. If marsh areas are gradually inundating due to rising sea level, they may suffer from erosion as increased water depths enable increased wave action on the marsh edges (Masselink and Hughes 2003; Simas et al. 2001). Erosion of the seaward margins of mangrove forests can take place as a consequence of a rising sea level, resulting in landward migration of the mangrove edge (Alongi 2008; Gilman et al. 2008). Vegetation of sloping sedimentary coasts has an important effect in reducing erosion and gully formation from heavy precipitation events and groundwater seeping, and in reducing the impact of wave action on the slope base.

Degradation of coral reef systems may result in more wave energy across the reef flat reaching the shore, increasing the potential for erosion (IPCC 2007b; Sheppard et al. 2005). The reduced calcification rates in the oceans due to climate change may lead to a reduction of coral skeleton density. This could increase the vulnerability of coral reefs to wave exposure and tropical storms, leading to increased coastal erosion (Hoegh-Guldberg et al. 2007). The rising sea level combined with increased tropical storm intensity also mean that coral islands are likely to experience significantly erosion and a possible reduction of island size (IPCC 2007b).

\section{Flooding}

The graduation of inherent hazards for flooding is related to the possibility of a sudden, abrupt and often dramatic inundation of a coastal environment caused by a short term increase in water level due to storm surge, extreme tides and seasonal variations (Mangor 2004). A gradual relative sea level rise will also lead to higher extreme water levels.

The flooding hazard is closely related to the geological layout with coastal plains, barriers, deltas and coral islands being particularly vulnerable (IPCC 2007b). In delta environments, a rising sea level combined with a storm surge, heavy precipitation and associated peak river flow can lead to extensive flooding. This is further exacerbated in areas with tropical cyclone activity, and increased cyclone intensity due to climate change is expected to increase flooding hazards (IPCC 2007b).

Tidal range influences the flooding hazard of coastal environments by affecting the daily and maximum water levels. Different arguments have been put forward about the relationship between tidal range and flooding hazards, but it is generally accepted that the flooding risk increases with decreasing tidal range (Thieler et al. 2000). This is the case, as there is only a certain, relatively low, probability that a storm will occur at the same time as a high tide. In micro- 
tidal environments, the water level is always near its maximum level and therefore has little space for further increase before passing the normal high tide level. In meso/macrotidal environments, water levels can most of the time increase significantly during storm events before reaching the high tide level (Thieler et al. 2000).

Marsh and mangrove environments are often flooded as part of their natural dynamics. It is well established that mangrove forests protects the coastline from tropical cyclone and flooding events, and degradation of these systems due to human activities may increase the extension and damage from flooding due to climate change. Some mangrove species seem to be more flood tolerant than others and some changes in community composition may happen as a result of climate change (Alongi 2008).

\section{Practical application and limitations}

The practical application of the assessment framework is done through the use of the CHW, which is shown in Fig. 4. The user starts in the centre of the CHW and then moves outwards, ending with the inherent hazard evaluations in the outermost circles. Starting from the centre, the coastal classification parameters come in the following order where each category is represented by a new circle: Geological layout, wave exposure, tidal range, flora/fauna, sediment balance and storm climate. The inherent hazard circles then come in the order: Ecosystem disruption, gradual inundation, salt water intrusion, erosion and flooding. Where the term "Any" is applied in the classification system, the user should simply continue with the parameter in the following circle. In the case of sloping rocky coasts, the user should follow the "A" (for Any) in the circle for wave exposure, for locations where no beach is present. With the presence of some kind of beach environment, the user should continue by evaluating the wave exposure levels.

The user of the assessment framework should ideally conduct a new assessment every time any of the classification parameters change significantly. For the practical application this means that a new hazard assessment is recommended every time the coastal environment changes character. Coastlines may also fall into several different categories as one move landwards. This can e.g. be the case for deltas, where the wave exposure decreases as one moves landwards into the delta or for barriers that may have a coastal plain or sloping sedimentary coast landwards of the barrier lagoon. The longshore shift from one coastal environment to another will often happen gradually over a coastal stretch, such as delta islands gradually turning into barriers some distance from the delta. In these cases, it may be difficult to determine when to apply the different categories. This should not lead to any significant errors, however, as the different sites will have very similar inherent hazard levels. In cases where the coastal site in question does not match any of the coastal categories in the assessment framework, the user should simply apply the category that best match the actual conditions.

The application of the assessment framework is complicated by the fact that many coastal environments have been altered by human activities to various degrees. These activities can affect the classification and inherent hazard graduation in two main ways, which should be considered by the user. Firstly, if the human alteration of the natural environment is happening outside the specific coastal site in question i.e. upstream river damming or nearby harbour construction, it may impact the classification through changes in the dynamic parameters and/ or sediment balance. Examples of this can found where river damming affects the sediment balance of a delta or where the presence of a harbour affects the wave exposure and sediment balance of a nearby coast. Generally, such long term, structural alterations of neighbouring or associated environments will automatically be incorporated in the classification system unless the alteration has taken place so recently that the site in question has not yet responded to the change. When using the assessment framework, it is therefore important to be aware of recent human alterations of nearby or related environments. Secondly, human activities may have altered the specific coastal site in question with the purpose of stabilizing the coastline or changing its land-use. If this alteration affects bio-physical parameters included in the classification system, such as by increasing the vegetation of a sloping soft rock coast or by carrying out beach nourishment, the site may temporally or permanently shift into a new classification category. If the alteration mainly affects bio-physical parameters that are not incorporated in the classification system or they alter the coastal environment to a condition outside its natural state i.e. by completely removing a mangrove forest in an otherwise natural mangrove area, the assessment framework will not be able to take these alterations into account.

\section{Conclusions}

The framework aims at providing a methodological foundation for simple assessment of inherent hazards in coastal environments under changing climatic conditions. It is intended to complement existing frameworks and methodologies for coastal vulnerability and risk assessment, and to provide a viable alternative for developing country planners that have difficulties applying existing frameworks due to lack of sufficient data and computing capacity. The assessment framework may provide less accurate hazard estimates than more sophisticated and data-intensive methods and is therefore mainly designed for meso-scale applications relevant for regional and national planning. As is the case for most other 


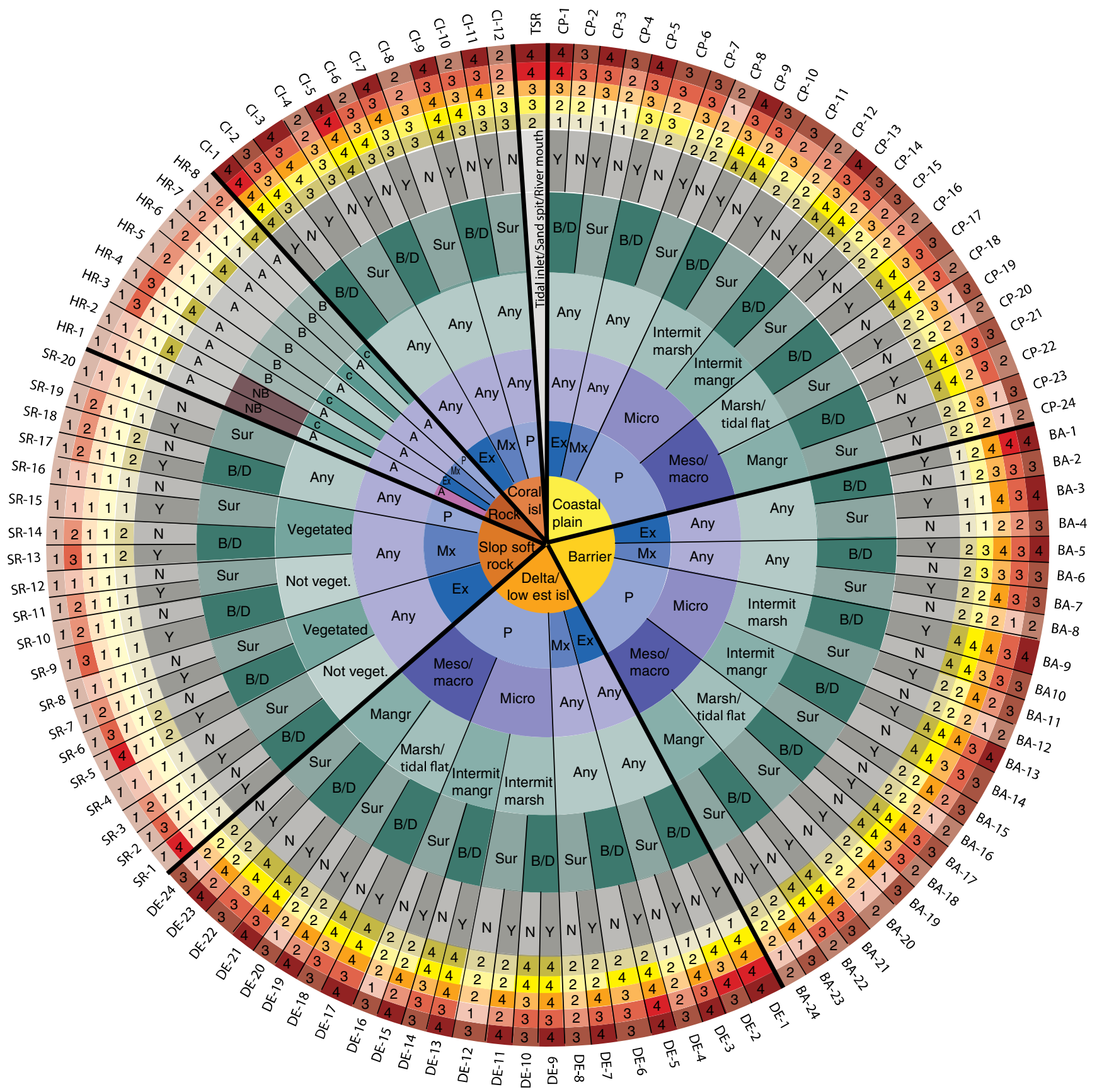

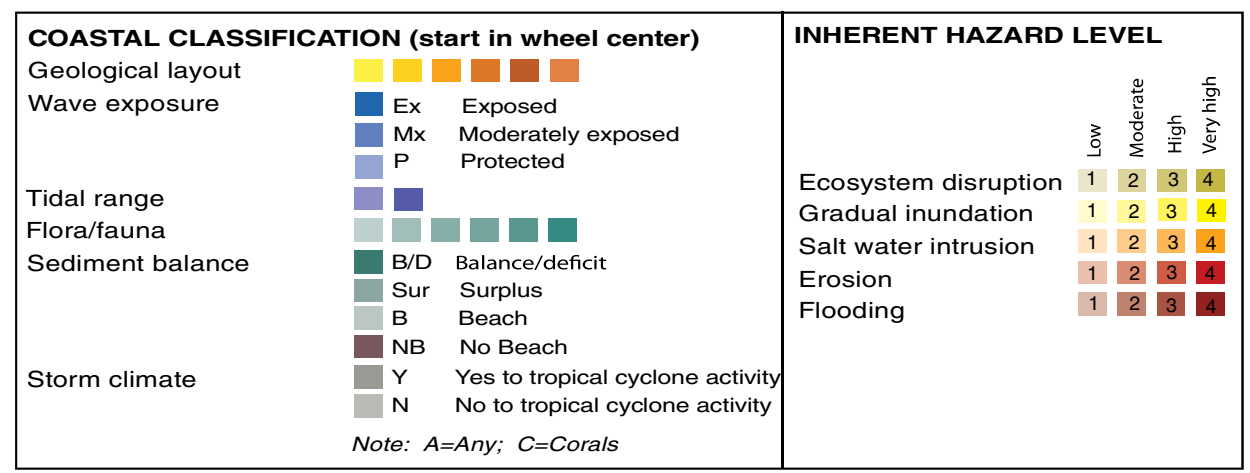

Fig. 4 The Coastal Hazard Wheel (CHW) 
indicator and index based approaches, it is a useful tool for scoping assessments and to support identification of vulnerable coastal areas and systems. For local development activities, a more detailed assessment is recommended in order to obtain indebt knowledge of the risk profile of the coastal site in question. To optimize the accuracy of the inherent hazard estimations, it is recommended to use a combination of remote sensing, onsite assessments, geophysical data and geological maps for the coastal classification. If an assessment is carried out primarily based on remote means, one should be aware of the associated uncertainties, especially related to the sediment balance estimates.

Acknowledgements I would like to thank the following persons for fruitful discussions and advice: Kirsten Halsnæs, Troels Aagaard, Karsten Mangor, Peter A. Klagenberg, Ulrich Elmer Hansen, Rasmus Ringgaard, Anders Bartholdy, Thomas Hjort Jensen.

Open Access This article is distributed under the terms of the Creative Commons Attribution License which permits any use, distribution, and reproduction in any medium, provided the original author (s) and the source are credited.

\section{References}

Alongi DM (2008) Mangrove forests: Resilience, protection from tsunamis, and responses to global climate change. Estuarine Coastal Shelf Sci 76:1-13

Brown AC, McLachlan A (2002) Sandy shore ecosystems and the threats facing them: Some predictions for the year 2025. Environ Conserv 29:62-77

Burkett V, Kusler J (2000); Climate change, potential impacts and interactions in wetlands of the United States. Journal of the American Water Resources Association 36, no 2.

Coastal Engineering Research Center (1984) Shoreline protection manual. US Army Corps of Engineers, Washington DC

Cowel PJ, Thom BG (1994); Morphodynamics of coastal evolution, In Carter RWG, Woodroffe, CD (ed) Coastal Evolution, Cambridge University Press.

Davis Jr RA, Fitzgerald DM (2004); Beaches and coasts. Blackwell Publishing.

Davies JL (1980); Geographical Variation to Coastal Development, 2nd Edition, Longman (Pearson Education Limited).

Douglas AE (2003) Coral Bleaching - how and why. Mar Pollut Bull 46:385-392

Ericson JP, Vorosmarty CJ, Dingman SL, Ward LG, Meybeck M (2006) Effective sea-level rise and deltas: Causes of change and human dimension implication. Global and Planetary Changes 50:63-82

Essink GHPO (2001) Improving fresh groundwater supply—problems and solutions. Ocean and Coastal Management 44:429-449

Gilman EL, Ellison J, Duke NC, Field C (2008) Threats to mangroves from climate change and adaptation options: A review. Aquat Bot $89: 237-250$

Guinotte JM, Buddemeier RW, Kleypas JA (2003) Future coral reef habitat marginality: Temporal and spatial effects of climate change in the Pacific basin. Coral Reefs 22:551-558

Hails AJ (1997) Wetlands, biodiversity and the Ramsar convention: The role of the convention on wetlands in the conservation and wise use of biodiversity. Ramsar Convention Bureau, Gland, Switzerland
Hallock P (2005) Global change and modern coral reefs: New opportunities to understand shallow-water carbonate depositional processes. Sediment Geol 175:19-33

Haslett SK (2009); Coastal systems. Routledge.

Hoegh-Guldberg O, Mumby PJ, Hooten AJ, Steneck RS, Greenfield P, Gomez E, Harvell CD, Sale PF, Edwards AJ, Caldeira K, Knowlton N, Eakin CM, Iglesias-Prieto R, Muthiga N, Bradbury RH, Dubi A, Hatziolos ME (2007) Coral reef under rapid climate change and ocean acidification. Science $318: 1737$

IPCC (2007a) Climate Change 2007: The physical science basis In: Solomon S, Qin D, Manning M, Chen Z, Marquis M, Averyt KB, Tignor M, Miller HL (eds) Contribution of the Working Group I to the Fourth Assessment Report of the Intergovernmental Panel on Climate Change. Cambridge University Press, Cambridge UK

IPCC (2007b) Climate change 2007: Impacts, adaptation and vulnerability. In: Parry ML, Canziani OF, Palutikof JP, van der Linden PJ, Hanson CE (eds) Contribution of the Working Group II to the Fourth Assessment Report of the Intergovernmental Panel on Climate Change. Cambridge University Press, Cambridge UK

Jennerjahn TC, Ittekkot V (2002) Relevance of mangroves for the production and deposition of organic matter along tropical continental margins. Naturwissensschaften 89:23-30

Lesser MP (2004) Experimental biology of coral reef ecosystems. J Exp Mar Biol Ecol 300:217-252

Mangor K (2004) Shoreline management guidelines. DHI Water \& Environment, Hørsholm

Masselink G, Hughes MG (2003); Introduction to coastal processes and geomorphology. Oxford University Press.

McMullen CP, Jabbour J (2009); Climate change science compendium. UNEP.

McWillams JP, Côté IM, Gill JA, Sutherland WJ, Watkinson AR (2005) Accelerating impacts of temperature-induced coral bleaching in the Caribbean. Ecology 86:2055-2060

Morris JT, Sundareshwar PV, Nietch CT, Kjerfve B, Cahoon DR (2002) Responses of coastal wetlands to rising sea level. Ecology 83(10):2869-2877

Nicholls RJ (2004) Coastal flooding and wetland loss in the $21 \mathrm{st}$ century: Changes under the SRES climate and socio-economic scenarios. Glob Environ Chang 14:69-86

Press F, Siever R (2001); Understanding earth. Freeman and Company.

Ramieri E, Hartley A, Barbanti A, Santos FD, Gomes A, Hilden M, Laihonen P, Marinova N, Santini M (2011); Methods for assessing coastal vulnerability to climate change, European Environment Agency, European topic centre on climate change impacts, vulnerability and adaptation.

Richards JA, Mokrech M, Berry PM, Nicholls RJ (2008) Regional assessment of climate change impacts on coastal and fluvial ecosystems and the scope for adaptation. Climate Change 90:141-167

Ross MS, Meeder JF, Sah JP, Ruiz PL, Telesnicki GJ (2000) The southeast saline Everglades revisited, 50 years of coastal vegetation change. J Veg Sci 11:101-112

Schwartz ML (2005); Encyclopaedia of coastal science. Springer.Sheppard C, Dixon DJ, Gourlay M, Sheppard A, Payet R (2005) Coral mortality increases wave energy reaching shores protected by reef flats: Examples from the Seychelles. Estuarine Coastal Shelf Sci 64:223-234

Sheppard CRC (2003); Predicted recurrences of mass coral mortality in the Indian Ocean. Nature 425, September 2003.

Simas T, Nunes JP, Ferreira JG (2001) Effects of global change on coastal salt marshes. Ecol Model 139:1-15 
Stive MJF, Aarninkoff SGJ, Hamm L, Hanson H, Larson M, Wijnberg KM, Nicholls RJ, Capbianco M (2002) Variability of shore and shoreline evolution. Coast Eng 47:211-235

Spencer T (1994) Tropical coral islands - an uncertain future? In: Roberts N (ed) The Changing Global Environment. Blackwell, Oxford

Stone GW, McBride RA (1998) Louisiana barrier islands and their importance in wetland protection: Forecasting shoreline change and subsequent response of wave climate. J Coast Res 14(3):900-915

Sun G, McNulty SG, Amatya DM, Skaggs RW, Swift LW Jr, Shepard JP, Riekerk H (2002) A comparison of watershed hydrology of coastal forested wetlands and the mountainous uplands in the Southern US. J Hydrol 263:92-104

Thieler ER, Willams J, Hammer-Klose E (2000), National assessment of coastal vulnerability to future sea-level rise, accessed online the 28-11-11 at http://woodshole.er.usgs.gov/project-pages/cvi/
Van Goor MA, Zitman TJ, Wang ZB, Stive MJF (2003) Impact of sealevel rise on the morphological equilibrium state of tidal inlets. Mar Geol 202:211-227

Wodroffe CD (1995) Response of tide-dominated mangrove shorelines in Northern Australia to anticipated sea-level rise. Earth Surf Process Landforms 20:65-85

Woodroffe CD, Nicholls RJ, Saito Y, Chen Z, Goodbred, SL (2006) Landscape variability and the response of Asian megadeltas to environmental change. In: Harvey N (ed) Global change and integrated coastal management: The Asia-Pacific region. Springer, New York, pp 277-314

Wright LD, Thom BG (1977) Coastal depositional landforms: A morphodynamic approach. Prog Phys Geogr 1:412-459

Zhu X, Linham MM, Nicholls RJ (2010) Technologies for climate change adaptation - Coastal erosion and flooding. UNEP Risoe Centre, Roskilde 